\title{
M1 Macrophage to M2 Macrophage Ratio Measurement
}

National Cancer Institute

\section{Source}

National Cancer Institute. M1 Macrophage to M2 Macrophage Ratio Measurement. NCI

Thesaurus. Code C156005.

The determination of the ratio of M1 macrophages to M2 macrophages present in a sample. 